\title{
SAÚdE MENTAL E O PROFISSIONAL DA ÁREA DE EDUCAÇÃO
}

\author{
Daniela Soares Santana ${ }^{1}$ \\ Fábio Antônio Sacramento Santana ${ }^{2}$ \\ Telma Regina dos Reis de Assis ${ }^{3}$
}

\begin{abstract}
Resumo
Este artigo discorre sobre Saúde mental e o profissional da área de educação pois falar de saúde mental na atualidade é uma questão muito delicada ainda mais quando direcionamos esse conceito para abordar a respeito dos profissionais ligados a área de Educação. A proposta é organizar o texto partindo do conceito para compreender o que é saúde mental assim como traçar o perfil 'saudável' de um profissional em educação, bem como conceituar através de teorias que é a depressão, seus principais sintomas, as formas que interfere na prática docente e consequentemente quais os riscos que trazem para a classe sob a responsabilidade do profissional doente. A metodologia aplicada neste artigo foi levantamento bibliográfico em livros, revistas, artigos e leituras a internet. Podemos afirmar que faz-se necessário uma avaliação constante e amorosa dos profissionais envolvidos no processo e envolva uma equipe multidisciplinar capacitada para identificar, mediar e indicar tratamento eficaz, sendo necessária a adoção de estratégias pensadas para saúde mental que envolvam todos os participantes das esferas educacionais, uma vez que, uma pessoa doente pode por meio do seu comportamento, opiniões ou atitudes, influenciar de forma direta ou indireta a todos os outros envolvidos nos círculos escolares. Diante do exposto, entendemos que o exercício da docência, no panorama educacional da atualidade, requer uma gama de qualidades pessoais, tornando-se compreensível que muitos docentes encontrem-se desmotivados e impossibilitados de exercer suas funções
\end{abstract}

Palavras Chave: Professor. Ensino e aprendizagem. Saúde mental.

\begin{abstract}
This article discusses mental health and the professional in the area of education because talking about mental health today is a very delicate issue even more when we direct this concept to address the professionals related to the area of Education. The proposal is to organize the text based on the concept to understand what mental health is, as well as to outline the 'healthy' profile of a professional in education, as well as conceptualize through theories that it is depression, its main symptoms, the ways that interferes in the teaching practice and consequently what risks they bring to the class under the responsibility of the sick professional. The methodology applied in this article was a bibliographic

\footnotetext{
${ }^{1}$ Mestre em Ciências da Educação pela Faculdade Interamericana de Ciências Sociales (FICS). Pós graduada em Supervisão Escolar, pela Universidade Federal de Feira de Santana. Pós graduada em Psicopedagogia Clínica e institucional pela Segmento Instituto de Educação. Professora da Rede Municipal de Santo Amaro. Coordenadora Pedagógica da Rede Municipal de Salvador. Email: daniela.soares.santana@gmail.com

2 Mestre em Ciências da Educação pela Faculdade Interamericana de Ciências Sociales (FICS). Bacharel em Administração, pela União das instituições Educacionais do Estado de São Paulo (UNIESP). Licenciado em Matemática pela Faculdade de Ciências da Bahia (FACIBA).Professor da rede Estadual de Educação da Bahia .

E-mail: mangoo17@yahoo.com.br

${ }^{3}$ Doutoranda em Ciências da Educação pela Faculdade Interamericana de Ciências Sociales (FICS). Mestre em Ciências da Educação pela Faculdade Interamericana de Ciências Sociales (FICS). Especialista em Metodologia e Didática do Ensino Superior pela Faculdade Católica de Ciências Econômicas da Bahia (FACCEBA). Licenciada em Pedagogia Plena pela Faculdade Regional de Filosofia, Ciências e Letras de Candeias (FAC). Licenciada em Matemática pela Universidade Salvador (UNIFACS). Docente pela Secretaria Estadual de Educação de Salvador Ba..Email:telmaassis@rocketmail.com
} 
survey of books, magazines, articles and readings on the internet. We can affirm that it is necessary a constant and loving evaluation of the professionals involved in the process and involve a multidisciplinary team trained to identify, mediate and indicate effective treatment, requiring the adoption of strategies designed for mental health that involve all participants in the educational spheres, since, a sick person can, through his behavior, opinions or attitudes, directly or indirectly influence everyone else involved in school circles. Given the above, we understand that the exercise of teaching, in today's educational landscape, requires a range of personal qualities, making it understandable that many teachers are discouraged and unable to exercise their functions.teaching, in the educational scenario of today, requires a range of personal qualities, it is understandable that many teachers are discouraged and little committed to their functions

Keywords: Professor. Teaching and learning. Mental health.

\section{Introdução}

A motivação desta pesquisa se deu pela necessidade de discutir sobre a depressão docente e os riscos para as classes. Pois a ignorância sobre as doenças mentais e principalmente sobre a depressão e o comportamento inadequado no ambiente de trabalho precisa ser discutida.

Vive-se por um processo de mudança real em todo planeta, e a educação não ficou de fora destas transformações. Os profissionais de educação em especial tiveram que se reinventar diante o novo quadro mundial levado pela Pandemia Corona Vlrus Disease (COVID) 19. Ainda não existem previsões de mudança ou melhora e os investimentos não conseguem conter as mudanças individuais geradas pelo isolamento a que todos foram forçados a ser submetidos. Diante do quadro de isolamento social e em tempos de aulas virtuais o profissional de educação viu-se num novo desafio.

Despreparado intelectualmente, financeiramente, espiritualmente e emocionalmente, o profissional foi obrigado a se tornar um multiprofissional ao qual teria que se adaptar a novas tecnologias e suas ferramentas sendo eloquente e direto diante câmeras. Câmeras adquiridas individualmente sem apoio, acesso a internet pago com as próprias posses, além de desenvolver técnicas diferenciadas para prender a atenção dos estudantes do outro lado da tela.

Neste contexto pode-se afirmar que a realidade é incerta e as necessidades são inumeráveis. Assim pode-se sugerir que as pessoas e principalmente os professores encontram-se num processo delicado que envolve a saúde mental e todas as consequências que o momento força a alguns uma pressão mais que normal a esta adaptação. Infelizmente, não existe uma orientação dos setores de saúde nas escolas que sejam capazes de orientar aos profissionais o quanto 
necessitam de ajuda para regular suas emoções ou senão buscarem apoio de psicólogos para seguirem com a mente saudável diante as dificuldades expostas.

\section{Conceito de saúde mental}

Uma série de fatos estão relacionados ao tema e se formos abordar todos os itens não conseguiríamos dar conta da infinidade de processos mentais relacionados a questão. Portanto vamos nos ater a uma construção baseada em estudos realizados por diversos autores e artigos científicos, afim de delimitar, descrever, direcionar, esclarecer e dimensionar os problemas que mais afetam a classe dos profissionais em educação.

Seguindo pela linha de raciocínio onde o conceito de saúde mental, nesta ocasião se faz necessário nos esbarramos em uma questão de inegável oportunidade e relevância porque, por mais que se busque, em contraste com o muito que se tem investido no desenvolvimento de modelos teóricos da doença mental, pouco se tem avançado no sentido de construir conceitualmente a saúde mental.

Considerando as importantes contribuições da filosofia, da psicanálise e das ciências sociais, ironicamente privilegia a doença em detrimento do trabalho teórico sobre a saúde. Quando se aborda em 'Saúde Mental', longe vem à mente 'Doença Mental'. Mas, a saúde mental implica muito mais que a ausência de doenças mentais. A cultura da sociedade em que vivemos é repleta de estigmas e facultam a quem procura ajuda o rótulo de doente mental, sem nem mesmo saberem seus conceitos, ordens e direcionamentos. Então, o que é ser saudável mentalmente?

Ser saudável hoje é ter o mínimo de capacidade em se relacionar com os próprios conflitos e frustrações. Porém, todos possuem limites e nem sempre as pessoas conseguem validar suas aflições e angustias da mesma forma, nem todos são iguais ou encontram os mesmos caminhos para vencer suas limitações. Uma série de emoções como alegria, amor, satisfação, tristeza, raiva... deixam em conflito uma mente dita saudável. Pessoas saudáveis devem ser capazes de enfrentar os desafios e as mudanças da vida cotidiana com equilíbrio e sabem procurar ajuda quando têm dificuldade em lidar com conflitos, perturbações, traumas ou transições importantes nos diferentes ciclos da vida.

Percebe-se que a saúde mental está relacionada as reações dos fatos que ocorrem na vida de uma pessoa e ao modo como direciona seus desejos, 
capacidades, ambições, ideias e emoções. Ter saúde mental, pode estar relacionado a estar bem consigo mesmo e com os outros, aceitar as exigências da vida, saber lidar com as emoções e também reconhecer seus limites buscando ajuda quando necessário.

\title{
A psicologia emocional
}

O que poderia ser essa inteligência emocional? Indivíduos emocionalmente inteligentes deveriam conhecer a expressão e a manifestação das emoções, sendo sensíveis a expressões falsas ou manipuladoras. Mas, será que essa regra é geral? Nem sempre isso acontece. As implicações de uma sociedade que ignora a empatia torna o indivíduo vulnerável as emoções e suas diferentes formas de expressão.

O conceito mais difundido para Inteligência Emocional foi proposto por Mayer e Salovey (1999 apud FREITAS; NORONHA, 2006), que assim a define:

[...] a capacidade de perceber acuradamente, de avaliar e expressar emoções; a capacidade de perceber e/ou gerar sentimentos quando elas facilitam o pensamento; a capacidade de compreender a emoção e o conhecimento emocional; e a capacidade de controlar emoções para promover o crescimento emocional e intelectual (Ibid., p.80).

As quatro áreas da Inteligência Emocional estão relacionadas com a qualidade das interações entre os indivíduos e o meio, sendo a Percepção, avaliação e expressão das emoções; a Emoção como facilitadora do pensamento; a Compreensão e análise das emoções e o Controle reflexivo das emoções. (BUENO; PRIMI, 2003).

Vale lembrar que estas

\begin{abstract}
Nesse sentido, a inteligência emocional associa-se à capacidade de reconhecer os significados das emoções e dos relacionamentos, raciocinar sobre eles e utilizar essa informação para orientar as ações de adaptação ao meio (MAYER, 1999 apud MUNIZ; PRIMI; MIGUEL, 2007).
\end{abstract}

Essa capacidade de adaptar-se ao meio possui consequências em todos os aspectos da sua vida, pois, é possível perceber e afirmar que os indivíduos "emocionalmente competentes" que conhecem e lidam bem com os próprios sentimentos e leem e consideram os sentimentos das outras - levam vantagem em qualquer campo da vida" (GOLEMAN, 1995, p.26),

Percebem-se dois aspectos da Inteligência Emocional para a personalidade: a capacidade de compreensão das próprias emoções - Inteligência Intrapessoal - e a capacidade de compreender as emoções dos outros - Inteligência Interpessoal. A 
Inteligência Intrapessoal, na visão de Gardner (1995), criador da Teoria das Inteligências Múltiplas, visa:

[...] acesso ao sentimento da própria vida, à gama das próprias emoções, à capacidade de discriminar essas emoções e, eventualmente, rotulá-las e utilizá-las como uma maneira de entender e orientar o próprio comportamento (GARDNER, 1995, p.28).

A característica inteligência intrapessoal é a facilidade de quem a possui em compreender e identificar as suas próprias emoções e em lidar com elas de forma adequada às várias situações e aos seus objetivos pessoais. Implica a necessidade de refletir e de autoavaliar.

Identificar seus desejos e seus afetos. As emoções que as levam a comportar-se de forma adequada ou inadequada diante conflitos ou situações corriqueiras da vida. Conhecer-se e perceber no outro características semelhantes ou não ao que para cada um possa parecer "normal"

[...] está baseada numa capacidade nuclear de perceber distinções entre os outros; em especial, contrastes em seus estados de ânimo, temperamento, motivações e intenções (...) permite que um adulto experiente perceba as intenções e desejos de outras pessoas, mesmo que elas os escondam. (GARDNER, 1995, p.27).

A capacidade do homem de inserir-se no meio em que vive e busca ser aceito através de suas ações, nos leva a refletir sobre o como perceber suas reais intenções. Não se conhece uma pessoa apenas por momentos, ninguém sabe do que o outro é capaz de fazer até que um momento de provas se apresente e desta forma possa-se ver a real natureza do indivíduo. Porém, cada situação é singular, e cada momento está repleto de motivações que devem ser levados em consideração antes de se julgar qualquer atitude ou pessoa.

Pode-se apresentar um conjunto de características dos portadores de Inteligência Interpessoal, ao afirmar que:

[...] a inteligência interpessoal propõe que sejamos emocionais [...] tomando por base a empatia e aptidões sociais que através de hábitos, atitudes e comportamentos [...] como ser prestativa, comportada, tratar as pessoas com consideração, ser humilde, atenciosa, simples, bem-humorada, disposta e que sabe elogiar. Em contrapartida, uma pessoa também pode ser rejeitada por outras pessoas se falar alto, impor sua vontade, contar vantagem, ser egocêntrico, se fazer de vítima, ser fofoqueiro e intriguista. (CABRAL, 2010, [s.p.]).

Pessoas são diferentes e apresentam também diferentes características. Um desses profissionais, sem dúvida, é o professor. E o local onde ele mais se relaciona é sua sala de aula - a classe, repleta de alunos, os interlocutores iniciais. Hoje, podemos afirmar que estamos num cenário atípico, porém problemas existem e 
tendem a agravar a relação docente/discente a partir do desrespeito ao professor, da desvalorização da profissão, jornada muito grande de serviço, baixos salários, acumulo de trabalho e jornada de trabalho excessiva, a violência social que ultrapassou os portões da escola com o tráfico de drogas além do descaso do governo e escolas desaparelhadas didaticamente que ajudam a deteriorar o seu clima emocional.

\section{Desgaste Emocional dos Professores}

Uma sociedade descontrolada, equivocada com seus próprios princípios trazem à tona pessoas desorientadas e frágeis. Não seria diferente dentro das instituições de ensino. Relações desconectadas com o respeito e a hierarquia que anteriormente pautavam os ditames das unidades de ensino, na atualidade demonstram toda sua degradação expostas nos jornais, telejornais, internet, expondo ao mundo as aberrações vividas no contexto social replicadas no ambiente escolar. Como ter então afetividade positiva e plena nos dias atuais dentro das classes, pois:

\footnotetext{
Alguns professores sentem que seu relacionamento com os alunos determina o clima emocional da sala de aula. Esse clima poderá ser positivo, de apoio ao aluno, quando o relacionamento é afetuoso, cordial. Neste caso, o aluno sente segurança, não teme a crítica e a censura do professor. Seu nível de ansiedade se mantém baixo e ele pode trabalhar descontraído, criar, render mais intelectualmente (SANTOS; SILVA, 2002, p.12).
}

Porém esse tipo de afirmação é relativo. Vários fatores podem levar os alunos a possuírem atitudes desordenadas na classe. Família é a principal razão que pode leva-lo a algum desajuste, mas podemos acreditar que outras situações independem da família e são geradas única e exclusivamente pela condição psicológica do estudante, que pode variar segundo sua personalidade ou perspectiva diante do professor, pois:

[...] a violência da sociedade, a marginalização de determinados coletivos de pessoas, as desigualdades sociais e a falta de recursos familiares e pessoais também contribuem para que as relações dentro da escola sejam potencialmente mais conflituosas (MARCHESI, 2008, p.62)

Administrar comportamentos atípicos, agitados e inquietos são outro desafio para os professores e mais do que constantes nas salas de aula, e esse fenômeno 
reporta a outra situação, igualmente nova, que é compreender e buscar ferramentas emocionais para trabalhar com os indivíduos que são colocados em sua responsabilidade entendendo essa realidade e conseguindo ser competente eficiente em sua abordagem.

Nos traz a tona a figura de um professor inabalável. Aquele ser que consegue discernir e realizar as maiores proezas no que diz respeito a afetividade. Muitas vezes o que as pessoas esquecem é que o professor é uma pessoa como outra qualquer. Com certezas e incertezas mas principalmente cheio de sentimentos e ocupando a posição de professor sempre almeja fazer o seu melhor e mostrar, mesmo diante de tantos conflitos sociais, o seu melhor resolvendo questões complexas e provando a sua competência.

Concorda-se com Salvaro (2009), em sua dissertação de mestrado, na qual descreve as doenças relacionadas com a prática docente, também cita a violência como fator estressante para os professores, quando ele cita que:

O aumento da violência nas instituições escolares tem se tornado um grande problema, sobretudo por seus efeitos sobre a segurança do trabalhador docente. Muitos professores são atingidos pela violência ora exposta na escola, quando essa violência não se encontra dentro da própria sala de aula. Muitas vezes os docentes são agredidos por alunos, pais de alunos, entre outros. A violência não é somente física, mas também há violência verbal e não verbal (SALVARO, 2009, p.50).

Conflitos são inerentes a sociedade e a escola é um espaço social repleto de experiências conflitantes. A representação familiar que constrói a personalidade do estudante é de suma importância para o andamento destes afetos, pois:

Muitos docentes necessitam assumir vários empregos, gerando uma
sobrecarga de trabalho que os impede, muitas vezes, de refletir sobre seu
processo de trabalho docente. O tempo gasto com o preenchimento de
relatórios, o aumento de horas de aula dos professores, as adaptações
constantes aos projetos políticos e os problemas das distâncias que o
docente necessita percorrer até o trabalho são condições de uma grande
parte dos docentes entrevistados (ibid., p. 38 ).

Esses problemas enfrentados pelos docentes ao longo dos anos, muitas vezes, evoluem para problemas de saúde física e mental. Não é raro ocorrer doenças relacionadas ao desgaste emocional de professores como ansiedade, stress, pânico, transtornos de personalidade e depressão. È cada vez mais comum encontrar professores que sofrem não só com distúrbios psicológicos mas também com alguns problemas físicos que também o afetam psicologicamente. 
[...] os docentes, em princípio, possuem reduzido conhecimento do que o processo de trabalho pode the trazer em longo prazo. Procuram conhecer e reconhecer-se doente quando a doença já se instalou, pois, preocupados com o seu trabalho, esquecem de vigiar a própria saúde. Quando o professor adoece, começa a perceber como muitos dos outros colegas também estão doentes, passando pelo mesmo processo de doença. Ibidem., p.81).

Os problemas físicos que também afetam psicologicamente, geralmente apontados dentre os vários padecimentos dos docentes, podemos discutir alguns: as Lesões por Esforços Repetitivos (LERs) e os Distúrbios Osteomusculares relacionados ao Trabalho (Dort) estão ligados aos problemas de postura e trabalho excessivo, que podem ser caracterizados por: tendinite, bursite e lombalgias.

As dores e a incapacidade física gerada por estes problemas tornam o profissional incapaz de ter uma ação efetiva diante seus deveres. Tais esforços repetitivos como a digitação, o escrever na lousa, o apagar seguidamente o quadro, dentre outros realizados pelos docentes podem desencadear os mais diversos e diferentes tipos de doenças osteomusculares. Verifica-se, ainda, que tais doenças trazem a tona um sentimento de incapacidade pessoal, uma vez que ao serem adquiridas o profissional é obrigado a realizar fisioterapias e terapias psicológicas para redimensionar suas ações.

A jornada longa de serviço em pé traz sobrecarga para a coluna e fadiga à musculatura. Vale lembrar, também, que a correção de provas e tarefas, a movimentação com livros e provas podem ocasionar problemas ortopédicos. Vale salientar que:

Dentre estas doenças que acometem os docentes, a síndrome do túnel do carpo é a neuropatia compressiva mais comum e resulta da compressão do nervo mediano no nível do punho dentro do compartimento limitado pelo ligamento transverso do carpo (ROBBINS, 1996, p.1161-1162).

Acredita-se que as causas deste tipo de lesão sejam a exigência da escrita e a posição e forças que devem ser feitas no ato de escrever prolongado, sendo apelidada de câimbra do escrivão. Outro fator importante no adoecer dos docentes é a hipertensão arterial sistêmica que, segundo Silva e Souza (2004, p.330), "[...] representa grave problema de saúde. Alguns fatores de risco para a doença são mais comuns em centros urbanos das metrópoles". O alto nível de stress ao qual são submetidos geram também os transtornos psicológicos.

Os transtornos psicológicos que afetam os docentes se justificam pelas repetidas situações estressantes que ele enfrenta na sala de aula e também fora 
dela. Essas situações exigem muito controle emocional, controle que acaba perdendo ao longo da sua trajetória docente. Sobre as doenças que acometem os professores, pode-se destacar que o existe é:

Professor fatigado, cansado, 'estoura' com facilidade com seus colegas com palavras indelicadas, docentes com semblante desfigurado pela dor da tendinite, da hérnia na coluna, da voz rouca, da depressão, enfim, são muitas as situações que podem ser 'lidas' no semblante, no olhar, no corpo do docente através da comunicação não verbal (SALVARO, 2009, p.43).

O descontrole emocional dos professores é:

[...] a situação deles (professores) se explica principalmente pelo contexto político e social; por isso, suas emoções não são apenas uma questão individual, devendo ser compreendidas de um enfoque histórico, interativo, sociológico, global e interpretativo (MARCHESI, 2008, p.62).

Vale ressaltar que um ambiente hostil assim como a perda de pessoas queridas, incertezas, conflitos interpessoais, carga de trabalho inadequada, falta de recompensa ou reconhecimento e conflitos de valores são fatores que fortemente desencadeiam o descontrole emocional. Configurando-se um local propício para eventuais crises e mais desgastes psicológicos.

\section{Controle emocional dos professores}

O controle emocional dos professores é fundamental para o ambiente educacional e para a construção de uma relação saudável com os alunos e, consequentemente, um adequado processo de ensino desta forma a busca do equilíbrio é fundamental por parte do professor, pois:

O professor pode ter um comportamento equilibrado ao responder aos desafios dos relacionamentos, quando ele é capaz de acolher e escutar os seus alunos. $E$, no processo da compreensão das emoções e dos sentimentos, viu-se que, ao entender o processo interior, o ser humano está mais preparado para responder aos desafios relacionais (BUSATO, 2006, p.65).

O ato de ensinar e de aprender é uma constante troca. È imprescindível que o professor seja um educador que enfrente desafios e compreenda que o conhecimento se processa através de valores que embasam e justificam a aprendizagem, nas relações interpessoais dos sujeitos envolvidos no processo e que o vivenciam em sala de aula (SANTOS; SILVA, 2002).

Como consequência do controle emocional, é de se esperar que os conflitos escolares e o desgaste dos docentes sejam diminuídos. Em uma sociedade cada 
vez mais complexa, competitiva e provocadora das relações da pessoa consigo mesma e com os outros, é fundamental ao professor aprender a lidar com suas emoções e sentimentos. Observa-se que alguns professores encontram dificuldades de natureza relacional na interação com os seus pares e com a comunidade educativa, mas principalmente com os seus educandos (BUSATO, 2006).

Alguns professores conseguem fazer predominar as emoções positivas em sua atividade profissional; outros, ao contrário, sentem-se oprimidos pelas exigências e pelas dificuldades de enfrentá-las, o que marca a prevalência do desânimo e da amargura (MARCHESI, 2008), que podem evoluir para problemas físicos e psicológicos. Por isso, é que se faz necessário diagnosticar os níveis de Inteligência Emocional dos professores, para que se possa inferir como os docentes compreendem suas próprias emoções e como eles lidam com as emoções dos outros.

\section{Perfil de um professor mentalmente saudável}

Refletindo para escrever sobre este item, me veio a cabeça uma missão impossível! É mediador entre pais, alunos, conhecimento, comportamento, formação de pensamento, cumpridor de horários cada vez mais densos, aplicador de técnicas e teorias embasadas em pessoas que dimensionam a educação de um ponto de vista fora da realidade local, articulador conceitual de tecnologias para suprir necessidades urgentes transformador de conteúdos enfadonhos em algo lúdico e interessante e ainda muito mais atitudes que devem nortear sua prática.

O professor precisa ensinar os alunos a pensar de forma crítica; a interagir com a sociedade; a compreender os motivo e objetivos que envolvem as atividades executadas na escola, além de estimular a participação dos alunos, sugerir tarefas interessantes, adaptar a atividades as capacidades do educando proporcionar a cooperação entre colegas e favorecer vivências de êxito escolar.

E para efetivar tais ações os conhecimentos trazidos pela Neuroeducação são indispensáveis, pois, fundamentam o professor sobre a plasticidade cerebral e sobre a necessidade de estimular o aluno para que este construa novos conhecimentos, interaja com a sociedade e modifique-a.

Em sua obra "A Epistemologia Genética” Piaget (1950) partiu de pesquisas pautadas no desenvolvimento infantil para explicar como o homem consegue alcançar níveis de conhecimento mais avançados. 
A origem do pensamento infantil foi seu ponto de partida para chegar a consciência do adulto, quando o pensamento fica mais elaborado. Outra teoria nos referência neste estudo é a sócio interacionista de Vygotsky [entre1920-1934] preconiza que o ensino se dá por meio da interação social, ou seja, o desenvolvimento cognitivo e consequentemente o aprendizado em matemática pode ser mais produtivo por meio de atividades em grupo, trocas de experiências entre alunos e aluno e professor. A aprendizagem e o desenvolvimento intelectual partem da interação social.

Diferente de Piaget Vygotsky defende que o desenvolvimento se dá por meio de experiências e interações entre indivíduos, os fatores sociais são fulcrais para esse desenvolvimento. Para o ensino da matemática o mais importante é que o aluno seja agente do seu conhecimento, as interações entre aluno e professor pressupõe um conhecimento entre os saberes preexistentes que os educandos possuem.

Desta forma pode-se dizer que os parâmetros que norteiam a teoria de Piaget afirmam que o aprendizado se dá por meio do desenvolvimento cognitivo, prédeterminado pelo desenvolvimento biológico, enquanto a teoria que norteia os estudos para Vygotsky as interações sociais e os contatos externos proporcionam o desenvolvimento e posteriormente são internalizados, porém em nas duas teorias o aluno é participante do processo de construção do conhecimento, coautor, ativo e questionador.

\section{Considerações}

No contexto estudado percebe-se a urgência de desmistificar as doenças mentais e a procura de ajuda de um profissional qualificado na área de saúde que seja capaz de auxiliar o profissional em educação a superar o momento de desequilíbrio em que possa se encontrar. A ideia de uma equipe multidisciplinar nas unidades vai além das possibilidades e interesse público, pois apesar de ser necessária, essa não é uma regra, uma vez que os estudos realizados ainda são poucos e não justificam um investimento real no orçamento dos órgãos competentes. Entretanto, essa não é uma questão apenas do presente, pois já vem de forma contextualizada na história da educação e dos profissionais que nela trabalham. 
Faz-se necessário destacar que apesar do assunto ser muito importante, ainda existe muito preconceito com as pessoas que frequentam especialidade médica voltada para desequilíbrios e problemas de ordem mental. Piadas de mau gosto e comparações sem sentido demostram como a sociedade é despreparada para auxiliar as pessoas que passam por desequilíbrios e problemas de ordem mental. Triste fato que expõe uma realidade cruel e forçam os profissionais a esconderem toda dor e sofrimento que cotidianamente são impelidos a enfrentar. A análise da profissão docente facilita uma reflexão crítica sobre as tensões e contradições que ocorrem na atividade dos professores que diante tantas exigências políticas, sociais e profissionais, impostas no exercício da profissão, requer uma diversidade de saberes que vão muito além de uma formação acadêmica.

O bem-estar do profissional é, no entanto, o resgate da sua autoestima, do seu status enquanto educador de toda sociedade, pois não existe profissional que se forme sem o compromisso do educador, perpassa por uma remuneração justa e adequada, com uma carga horária humana onde o professor possa se sustentar e a sua família sem precisar trabalhar em vários lugares ao mesmo tempo, para que finalmente o professor possa ter uma vida social que corresponda ao bem estar de qualquer outro profissional.

Pode-se afirmar que a qualidade do ensino é significativamente afetada pelas condições de trabalho e saúde dos docentes. Portanto, considerar a docência como um trabalho relevante a sociedade torna-se mais uma vez, necessária uma reavaliação sistemática e global da situação individual e coletiva dos profissionais envolvidos na área. A análise das condições de trabalho e seu impacto no bemestar e na qualidade de vida dos professores pode abrir vias eficazes de prevenção e promoção da saúde mental na classe dos educadores. As emoções dos envolvidos no processo educacional expressam uma interação que se interdependem. A somatização do sofrimento ultrapassa as linhas do corpo físico e reagem de forma sintomática em atitudes contrária ao "normal" existente no contexto escolar. 


\section{Referências}

BUENO, J. M. H.; PRIMI, R. Inteligência emocional: um estudo de validade sobre a capacidade de perceber emoções. Porto Alegre: Revista Psicologia: reflexão e crítica, 2003

BUSATO, A. Pedagogia do aconselhamento e formação docente: educando emoções e sentimentos. Dissertação (Mestrado) - Pontifícia Universidade do Paraná, Curitiba, 2006.

GARDNER, H. Inteligências Múltiplas: a Teoria na Prática. Porto Alegre: Artes Médicas, 1995.

FREITAS, F. A.; NORONHA, A. P. P. Inteligência emocional e avaliação de alunos e supervisores: evidências de validade. São Paulo: Revista Psicologia: teoria e prática, 2006.

GOLEMAN, D. Inteligência emocional: a teoria revolucionária que redefine o que é ser inteligente. 69. ed. Rio de Janeiro: Objetiva, 1995.

MARCHESI, A. As emoções na docência. Porto Alegre: Revista Pátio, 2008.

MUNIZ, M.; PRIMI, R.; MIGUEL, F. K. Investigação da inteligência emocional como fator de controle do stress em guardas municipais. São Paulo: Revista Psicologia: teoria e prática, 2007.

ROBBINS, S. L; COTRAN, R.; KUMAR, V. Patologia Estrutural e funcional. 5. ed. Rio de Janeiro: Guanabara Koogan, 1996

SALVARO, M. S. Processo de trabalho docente: relação entre o ser e o adoecer. Dissertação (Mestrado) - Universidade do Extremo Sul Catarinense, Criciúma, 2009

SANTOS, R. M.; SILVA, A. C. Relação professor aluno: uma reflexão dos problemas educacionais.Trabalho de Conclusão de Curso (Graduação em Pedagogia) - Centro de Ciências Humanas e Educação. Belém: Universidade da Amazônia,, 2002.

SILVA, J. L. L.; SOUZA, S. L. de. Fatores de risco para hipertensão arterial sistêmica versus estilo de vida docente. [s.l.]Revista Eletrônica de Enfermagem, 2004

ZENHAS, A. Inteligência interpessoal. Porto: Porto Editora, 2005. 